\title{
Chylopericardium as a complication of mitral valve replacement
}

\author{
YARON BAR-EL, ARAM SMOLINSKY, ALON YELLIN \\ From the Departments of Thoracic and Cardiovascular Surgery, Chaim Sheba Medical Center, Tel Hashomer, \\ Israel
}

ABSTRACT A patient developed chylopericardium after mitral valve replacement. Although there was early relapse with cardiac tamponade it eventually resolved with conservative management consisting of tube drainage initially and a medium chain triglyceride diet for two months.

Chylopericardium as a complication of cardiac surgery is a rare entity, first described in 1971 by Thomas and McGoon.' The aetiology of chylopericardium is not clear, and there is no general agreement about its management. We report for the first time chylothorax as a complication of mitral valve replacement surgery in a 39 year old woman, and discuss the management of this condition.

\section{Case report}

A 39 year old woman who had had rheumatic fever at the age of 25 years developed exertional dyspnoea and nocturnal substernal pain 10 years later. Cardiac catheterisation showed moderate to severe mitral stenosis. In February 1986 the patient underwent an uneventful prosthetic mitral valve replacement. She was discharged 10 days later on a regimen of digoxin, warfarin, and chlorthalidone.

The patient was readmitted three weeks later because of recurrent substernal pain, nausea, and increasing fatigue. On admission she had slight dyspnoea and orthopnoea. Her blood pressure was $90 / 60 \mathrm{~mm} \mathrm{Hg}$ and heart rate 110 beats/ min, and her temperature was normal. No pulsus paradoxus was detected. The liver was enlarged by $9 \mathrm{~cm}$, and a hepatojugular reflux was present. She had bilateral pretibial oedema.

The full blood count and blood chemistry were normal, and urine analysis gave normal results. Her electrocardiogram showed normal sinus rhythm, with low voltage complexes. Chest radiography showed an enlarged cardiac silhouette (figure) and echocardiography a large pericardial effusion.

The findings were thought to indicate a severe postpericardiotomy syndrome, and the patient was treated with prednisone (40 mg/day), diuretics, and digoxin. Ten days later she became profoundly dyspnoeic and hypotensive, and cardiac tamponade was diagnosed. Pericardiocentesis yielded $2750 \mathrm{ml}$ of milky fluid. After the procedure her condition

Address for reprint requests: Dr Yaron Bar-El, Department of Cardiac Surgery, Chaim Sheba Medical Center, Tel Hashomer 52621, Israel.

Accepted 15 September 1988 improved considerably. Laboratory analysis of the aspirated fluid disclosed chylomicrons, confirming the diagnosis of chylopericardium. An indwelling catheter was left in the + pericardial space, and a medium chain triglyceride diet was initiated. The volume of fluid drained decreased progres- $\rightarrow$ sively from about $900 \mathrm{ml}$ on the day after pericardiocentesiso to $50 \mathrm{ml}$ eight days later. Drainage ceased after 10 days and. the catheter was removed. An echocardiograph at that timec showed minimal pericardial fluid. The patient was discharged? with instructions about a low fat diet and a medium chain triglyceride supplement.

One month after discharge she was readmitted withdyspnoea, engorged neck veins, and substernal pain $\infty$ Echocardiography showed a large pericardial effusion, with $^{\circ}$ compression of the right ventricle. A second pericardiocentesis yielded $1600 \mathrm{ml}$ of chyle. About $120 \mathrm{ml}$ of chyle was drained each day for the next seven days. Drainage ceased completely after 10 days, and the drain was then removed. Ang echocardiograph one week later showed no fluid in the pericardium, and the patient was discharged. After thorough questioning she had admitted to not following the recom $\overrightarrow{\overrightarrow{0}}$ mended diet after her first discharge. This time, however, she

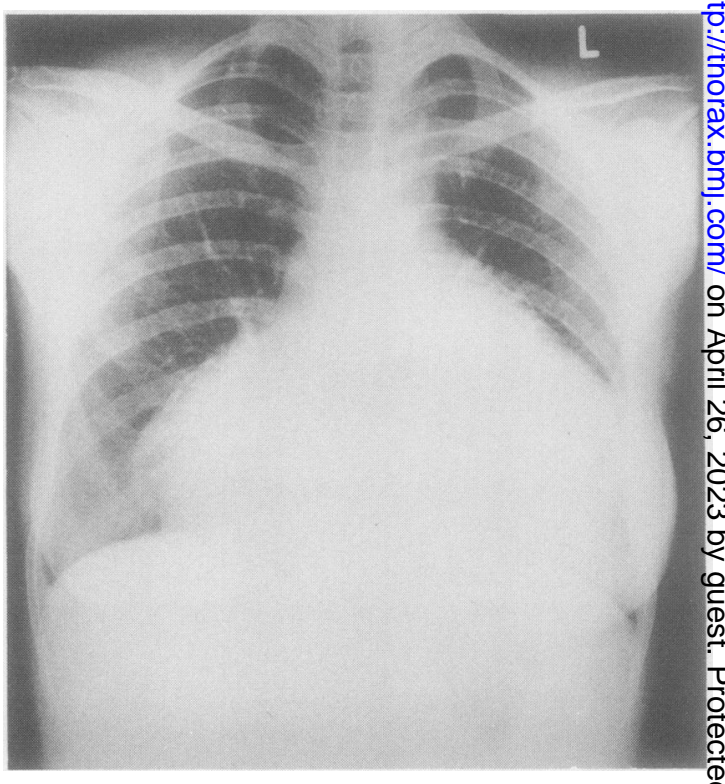

Chest radiograph taken at the first admission, showing the enlarged cardiac silhouette of cardiac tamponade. 
did adhere to the medium chain triglyceride diet, continuing it for four more weeks. Her subsequent course was uneventful. Eighteen months after surgery she is well, with no signs of pericardial effusion.

\section{Discussion}

The papers that followed the first report of a case of chylopericardium after cardiac surgery' have shown that this complication can occur at any age and after any cardiac operation..$^{2-10}$ Nevertheless, most cases have been associated with surgery for congenital heart disease. A single case of chylopericardium occurred after aortic valve replacement ${ }^{2}$ and chylomediastinum, but no chylopericardium, developed after mitral valve replacement. ${ }^{9}$ To our knowledge ours is the first case of chylopericardium associated with mitral valve replacement.

The aetiology of postoperative chylopericardium is still obscure. Thomas and McGoon found thrombosis of the left subclavian vein produced by an external jugular vein catheter, and they suggested obstruction to thoracic duct flow leading to chylopericardium.' The same mechanism has been proposed by others. ${ }^{25}$ Our patient had neither a left subclavian vein catheter nor signs of subclavian vein thrombosis. Chylopericardium may be due to injury to the thoracic duct caused by direct trauma resulting from extensive posterior mediastinal dissection ${ }^{310}$ or by the passage of caval tapes. ${ }^{378}$ Injury to the thoracic duct, however, usually results in rapid accumulation of chyle in the pericardium in the immediate postoperative period, and necessitates thoracic duct ligation for control. ${ }^{1245}$ As tapes were passed around the cavae in this case, and as the accumulation of chyle was slow, we assume that one or more of the variantly located small chyle ducts were injured. ${ }^{\text {s }}$

There is some disagreement about the optimal management of postoperative chylopericardium. Initially most authors advocated thoracic duct ligation for all cases ${ }^{49}$ but good results have been reported more recently with conservative treatment consisting of pericardial drainage and a diet low in fat and high in medium chain triglycerides. ${ }^{6-8}$ In the present case, despite potentially fatal tamponade, conservative treatment was instituted. Chronic tamponade recurred after what seemed to be a complete initial recovery, but this was probably because the patient had not followed the diet, which is unpalatable; subsequent compliance resulted in complete recovery.

We have presented the first case of chylopericardium occurring after mitral valve relacement. The patient developed life threatening tamponade four weeks after an uneventful recovery from surgery. Conservative treatment with tube drainage initially and a medium chain triglyceride diet produced a successful outcome.

\section{References}

1 Thomas CS, McGoon DC. Isolated massive chylopericardium following cardiopulmonary bypass. J Thorac Cardiovasc Surg 1971;61:945-8.

2 Kansu E, Fraimow W, Smullens SN. Isolated massive chylopericardium. Chest 1977;71:408-10.

3 Pollard WM, Schhuchmann GF, Bowen TE. Isolated chylopericardium after cardiac operations. J Thorac Cardiovasc Surg 1981;81:943-6.

4 Lee Y, Lee WK, Doromal N, Ganepola GAP, Hutchinson J. Cardiac tamponade resulting from massive chylopericardium after an aorto-coronary bypass operation. $J$ Thorac Cardiovasc Surg 1987;94:449-50.

5 Rose DM, Colvin SB, Danlowicz D, Isom OW. Cardiac tamponade secondary to chylopericardium following cardiac surgery: case report and review of the literature. Ann Thorac Surg 1982;34:333-6.

6 Hamilton JRL, Mulholland HC, Cleland J. Chylopericardium: a rare complication of a Waterston shunt. Br Heart $J$ 1985;54: 548-9.

7 Hawker PE, Cartmill TB, Celermaier JM, Bowdler JD. Chylus pericardial effusion complicating aorta-right pulmonary artery anastomosis. J Thorac Cardiovasc Surg 1972;63:491-4.

8 Jacob T, de Laval M, Stark J, Waterston DJ. Chylopericardium as complication of aorto-pulmonary shunt. Arch Surg 1974;108: 870-1.

9 Wong PHC, Mok CK, Ong GB. Chylomediastinum: an unusual complication after mitral valve replacement. Aust NZ J Surg 1982;52:560-1.

10 Delaney A, Daicoff GR, Hess PJ, Victorica B. Chylopericardium with cardiac tamponade after cardiovascular surgery in two patients. Chest 1976;69:381-3. 